\title{
A ANÁLISE ECONÔMICA DO DIREITO APLICADA À TRIBUTAÇÃO COMO FORMA DE CONCRETIZAÇÃO DOS DIREITOS FUNDAMENTAIS
}

\author{
Hérica Cristina Paes Nascimento* \\ Valéria Cristina Garcia Cabral* \\ Vithor Assunção Sousa*
}

\begin{abstract}
Resumo: A Análise Econômica do Direito (AED) tem-se se mostrado um campo de análise para a promoção da justiça e efetivação das garantias fundamentais consagradas num Estado Democrático de Direito, notadamente frente às novas tecnologias. Essa ferramenta do Direito também se mostra eficiente na busca pela máxima aplicabilidade dos direitos fundamentais, a partir da observância de um comportamento tributário mais eficiente, capaz de conferir a máxima concretude aos preceitos constitucionais abstratos. Objetiva-se no presente artigo trazer reflexões acerca da concretização dos direitos fundamentais sob a ótica da Análise Econômica do Direito aplicada à tributação.
\end{abstract}

Palavras-chave: Tributação; Direitos Fundamentais; Tecnologias; Economia; Constituição.

\section{ECONOMIC ANALYSIS OF LAW APPLIED TO TAXATION AS A FORM OF CONCRETING FUNDAMENTAL RIGHTS}

\footnotetext{
* Mestranda em Direito da Empresa e dos Negócios na Universidade do Vale do Rio dos Sinos - UNISINOS. Possui Pós-graduação "Lato Sensu" em Direito e Justiça do Trabalho pela Faculdade Sul-Americana - FASAM (2016). Graduada em Direito pela Instituto de Ensino Superior de Rio Verde (2012). Foi Assessora Jurídica no Ministério Publico do Trabalho em Rio Verde-GO de 2013 a 2016. Atualmente é Procuradora Jurídica da Universidade de Rio Verde - UniRV. Advogada; e-mail: hericacpnascimento@gmail.com.

* Mestranda em Direito da Empresa e dos Negócios pela UNISINOS, especialista em Direito Empresarial pela Universidade de Rio Verde, advogada e professora na Universidade de Rio Verde. E-mail: valeria.cabral@unirv.edu.br.

* Mestrando em Direito da Empresa e dos Negócios na Universidade do Vale do Rio dos Sinos (2020); PósGraduado em Direito Penal pela Faculdade Damásio de Jesus de São Paulo (2018); Pós-Graduado em Direito Administrativo e Licitações pela Faculdade Única de Ipatinga-MG (2019); Servidor público pela Universidade de Rio Verde (2016); Advogado; Membro da comissão de Esportes e Lazer e da comissão do Agronegócio da OAB, ambas da subseção de Rio Verde-GO; e-mail: vithorassuncao13@gmail.com.
}

\section{Revista Brasileira de Direitos e Garantias Fundamentais | e-ISSN: 2526-0111| Encontro}

Virtual | v. 6 | n. 2 | p. 39 - 56| Jul/Dez. 2020. 
Abstract: The Economic Analysis of Law (AED) has shown itself to be a field of analysis for the promotion of justice and the realization of fundamental guarantees enshrined in a Democratic State of Law, nod. This tool of law is also efficient in the search for the maximum applicability of fundamental rights, from the observance of a more efficient tax behavior, capable of conferring maximum concreteness to abstract constitutional precepts. The objective of this article is to bring reflections about the realization of fundamental rights from the perspective of the Economic Analysis of the Right applied to taxation.

Keywords: Taxation; Fundamental Rights; Technologies; Economy; Constitution.

\section{INTRODUÇÃO}

A concretização dos direitos fundamentais como forma de garantir e promover a dignidade da pessoa humana é uma tônica que vem sendo estruturada com a virada kantiana no pós segunda guerra até os dias atuais. Tal condição se mantém também nos dias atuais, notadamente com o uso das chamadas "novas tecnologias".

O ser humano, foco principal do qual constitui a sociedade, as organizações e tudo quanto mais, é ator social de diversas formas e vertentes, seja como trabalhador, contribuinte, empresário, pai de família, integrante de grupos associativos e de interesses em comum dentre outros. Disso, nota-se a variada gama de institutos jurídicos criados de forma a regulamentar as interações sociais e organizar a vida em sociedade.

Nesse sentido, ao considerar a finalidade principal buscada pelo homem, qual seja, seu bem-estar social, por meio da realização de suas conquistas sejam elas quais forem, é necessário travar um diálogo com as várias vertentes de estudos existentes, seja do ponto de vista da sociologia, da filosofia, do direito ou das diversas ciências humanas e sociais em geral.

Aqui, destaca-se a importância de uma análise interdisciplinar do direito com vistas à máxima concretização das garantias fundamentais, o que atrai a temática para o olhar da Análise Econômica do Direito e seus pressupostos "a partir dos estudos desenvolvidos por 
Richard Posner, com a finalidade de conjugar a investigação jurídica à econômica na construção de premissas sólidas e eficientes " (OLIVEIRA; PAYÃO, s.d.).

A princípio, será desenvolvida breve exposição a respeito da origem e das premissas da Análise Econômica do Direito, bem como da importância de um estudo interdisciplinar do Direito, de forma a se alcançar a máxima eficiência, não só econômica, mas também social quando da efetiva observância das garantias fundamentais, num mundo cada vez mais tecnológico.

Assim, seguir-se-á com uma breve análise acerca dos direitos fundamentais e a necessidade de uma maior concretização destes, aliando a essa finalidade uma tributação justa, eficiente, sem onerar demasiadamente os administrados, de maneira a influenciar na concretização dos direitos fundamentais.

Ao final, pretende-se demonstrar a viabilidade de se aplicar os preceitos da Análise Econômica do Direito na tributação como forma de garantir e promover os direitos fundamentais, frente às novas tecnologias, com o melhor aproveitamento dos recursos dispendidos para tanto, chegando-se, assim, à máxima eficiência nesta seara.

\section{ANÁLISE ECONÔMICA DO DIREITO}

Como bem pontuam Oliveira e Payão (s.d., p. 2) a análise econômica do direito "ventila o propósito de introduzir uma metodologia que contribua significativamente para a compreensão dos fenômenos sociais auxiliando na tomada racional de decisões jurídicas", tudo com vistas a tornar as normas mais eficientes não só do ponto de vista da sua aplicação, mas da efetividade dos institutos que se buscaram imprimir na sociedade com aquela norma.

Apesar de as críticas que se possam fazer acerca da Análise Econômica do Direito, notadamente de que esta desprezaria conceitos caros ao Direito e justiça, é importante salientar que para se chegar à máxima dimensão da justiça deve-se observar a eficiência como um de seus critérios para tal intento, uma vez que distribuir "de forma eficiente os recursos é a mais pura expressão de justiça distributiva", de forma que:

Revista Brasileira de Direitos e Garantias Fundamentais | e-ISSN: 2526-0111| Encontro Virtual | v. 6 | n. 2 | p. 39 - 56| Jul/Dez. 2020. 


\begin{abstract}
Aliar Direito e Economia é uma tentativa de rediscutir a cientificidade do Direito, imprimindo um pragmatismo às regras jurídicas. Não se pode fechar os olhos para a inevitável conclusão de que Direito e Economia caminham de "mãos dadas", sempre em busca da valorização do ser humano, sendo este o centro de convergência dessas ciências. (LEURQUIN e VIEIRA, 2011).
\end{abstract}

Assim, vislumbra-se de maneira crescente a interdisciplinaridade entre o direito e demais ramos do conhecimento, sendo que dentre eles destaca-se a economia, para a qual se dará destaque neste trabalho, tudo de forma a conferir maior amplitude e aplicabilidade das normas. Nesse sentido:

O direito parte de uma perspectiva mais objetiva, consistente na arte de regular o comportamento humano. A economia, por sua vez, é ciência que estuda os mecanismos indutores ou não por trás do comportamento humano em um mundo de recursos escassos. E analisar o direito sob a perspectiva econômica é empregar instrumentos teóricos e empíricos econômicos e ciências afins para expandir a compreensão e o alcance do direito, aperfeiçoando o desenvolvimento, a aplicação e a efetividade da norma jurídica (OLIVEIRA e PAYÃO, s.d.).

Trazer para o Direito vertentes de análise de outras áreas do conhecimento de forma a potencializá-lo, apesar de ser benéfico e progressista, também pode apresentar resistência por parte de autores há muito consagrados, bem como de institutos jurídicos tidos por imutáveis, dada a sua alta relevância e historicidade.

De fato, da comparação à primeira vista que se faz entre o Direito e a Economia, vêse que enquanto a Economia se mostra eminentemente matemática, empírica e científica, o Direito se mostra exclusivamente verbal, hermenêutico e pautado pela justiça. (SALAMA, 2007).

Entretanto, isso não deve servir de pressuposto válido para afastar essa interação, mormente quando o que se busca não é a desconstituição de princípios e normas arduamente conquistados e consagrados, mas sim trazer um olhar que agregue e aponte o caminho da máxima eficiência, ao mínimo custo possível, não só do ponto de vista da aplicação da norma mas, antes de tudo, até mesmo de sua criação, situação que aponta inclusive para um processo legislativo mais objetivo, eficiente e menos oneroso, considerando que a "formulação de uma regra eficiente em uma situação específica pode contribuir para a formulação de políticas públicas melhores e mais justas", uma vez que “o formulador de política pública que persegue 
objetivos não eficientes deve ter ciência dos custos que impõe à sociedade”. (SALAMA, 2007).

Assim, "a questão, portanto, não é substituir a discussão da justiça pela discussão da eficiência, mas sim enriquecer a gramática jurídica integrando a discussão da eficiência na discussão do justo". (SALAMA, 2007).

Dessa forma, relacionar o direito à economia pode auxiliar os governantes, "não só para lhes explicar os efeitos de uma política sobre a eficiência do uso dos recursos disponíveis, senão também no que se refere à identificação dos efeitos sobre a distribuição dos gastos e da riqueza". (SANTOS FILHO, 2016).

Para tanto, necessário se faz contextualizar a análise econômica do direito com os seus pressupostos básicos, delineando os aspectos dessa interação.

A análise econômica do direito surgiu nos Estados Unidos, nas Universidades de Chicago e Yale, e teve como seus principais precursores teóricos Aaron Director, Ronald Coase, Guido Calabresi, Gary Stanley Becker e Richard Allen Posner, concretizando o domínio da análise econômica do direito, conhecida como Law ad Economics (SANTOS FILHO, 2016), difundindo-se pelo país para depois se espalhar pelo mundo, ganhando mais visibilidade nos países de tradição de Direito Continental, inclusive no Brasil, desde os anos 1980. (SALAMA, 2007).

O economista Ronaldo Coase, em 1937 publicou seu trabalho intitulado The nature of the firm, no qual explica os conceitos dos custos de transação, bem como acerca dos limites e características das empresas. (SANTOS FILHO, 2016).

Já entre os anos de 1940 e 1950 o economista Aaron Director fundou, na Universidade de Chicago o campo da Law and Economics, com estudos focados em métodos científicos da economia como estatísticas e teoria do preço e sua aplicação no pensamento jurídico. (SANTOS FILHO, 2016).

Em 1960 Ronald Coase ganhou notoriedade ao apresentar o seu teorema na publicação de The problem of social coast, no qual "afirma que os direitos de propriedade devem ser bem definidos para superar as externalidades previstas no mercado". (SANTOS FILHO, 2016).

\section{Revista Brasileira de Direitos e Garantias Fundamentais| e-ISSN: 2526-0111| Encontro Virtual | v. 6 | n. 2 | p. 39 - 56| Jul/Dez. 2020.}


Guido Calabresi, em 1970 publicou o trabalhado The cost of accidents: a legal and economic analysis, no qual analisa sob a ótica da teoria econômica a responsabilidade e a forma de distribuir o risco dos acidentes, bem como os custos destes, de forma a evitar que voltem a ocorrer acidentes. (SANTOS FILHO, 2016).

Ocorre que, somente em 1973, com a publicação do Economic Analisys of Law, de Richard Posner, que foi consolidado e maior difundido o movimento da análise econômica do direito (SANTOS FILHO, 2016). Referida obra "representou um importante passo para a difusão da AED, tendo em vista que serviu como um manual que consolidou as teorias e serviu de guia para os estudantes de Chicago". (HEINEN, s.d.).

Dessa construção sintetizaram-se a Teoria dos Custos de Transação, a Teoria do Agente, a Teoria da Escolha Pública e a Teoria dos Jogos, as quais ponderam sobre a relevância de cinco conceitos centrais: escassez, maximização racional, equilíbrio, incentivos e eficiência. (SALAMA, 2007).

Salama (2007, p. 17) ao escrever sobre a escassez explica que os recursos são finitos, situação que obriga os agentes a equacionarem sua alocação, o que importa dizer que nem todos os desejos e objetivos poderão ser atendidos, ou seja, "nem tudo pode ser feito ou produzido; tudo tem um custo; e cada centavo gasto em uma determinada atividade, é o mesmo centavo que não é gasto em todas as demais."

Ao discorrer sobre a maximização racional Salama explica que a premissa comportamental é a de que os indivíduos sempre farão escolhas que atendam aos seus interesses pessoais, independentemente de quais sejam, de forma a maximizar seu bem-estar, mas ao menor custo possível. Assim, "a adoção do conceito de maximização racional indica que, na formulação de teorias, se partirá da premissa de que os indivíduos calculam para alcançarem os maiores benefícios aos menores custos”. (2007, p. 17-21).

Sobre esse ponto da maximização racional Salama explica que esta se dá de maneira instrumental, e não será necessariamente sempre assertiva ou completa dadas das limitações cognitivas dos seres humanos, mas estes buscarão sempre tomar a melhor decisão com o mínimo de riscos e custos possíveis. (2007, p. 19-20).

Outro conceito necessário de ser explicado é o do equilíbrio, "que é o padrão comportamental interativo que se atinge quando todos os atores estão maximizando seus

\section{Revista Brasileira de Direitos e Garantias Fundamentais | e-ISSN: 2526-0111| Encontro Virtual | v. 6 | n. 2 | p. 39 - 56 | Jul/Dez. 2020.}


próprios interesses simultaneamente" (SALAMA, 2007). Esse fenômeno deve ser melhor analisado e compreendido, uma vez que da interação dos indivíduos em busca da maximização de seus interesses vários são os conflitos que surgem, de modo que os comportamentos, as leis e os resultados fatalmente acabarão se modificando, uma vez que vão se afastando do ideal de bem-estar inicialmente formado por aqueles atores sociais.

O conceito de incentivos sugere a ideia de que os sujeitos também podem responder a eles como estímulos para uma certa conduta.

Portanto, como forma de estimular o cumprimento de determinada regra que o ordenamento jurídico venha a criar devem ser criadas formas capazes de incentivar os indivíduos de responderem positivamente a tal instituto, chegando-se ao seu escopo inicial quando da criação da norma.

Em relação à eficiência pode-se dizer que esta se relaciona com a máxima obtenção de riqueza e do bem-estar com o mínimo custo social possível, situação que denota que "um processo será considerado eficiente se não for possível aumentar os benefícios sem também aumentar os custos". (SALAMA, 2007).

Uma análise mais detida da eficiência exige uma abordagem pelas acepções do tipo Pateriana e de Kaldor-Hicks, onde na eficiência considerada ótima de Pareto uma transação seria eficiente quando, "após melhorar a situação de um dos agentes, não se piora a situação do outro" (LEURQUIN e VIEIRA, 2011). Já a eficiência de Kaldor-Hicks trata da compensação como forma de se chegar ao bem-estar, de modo que se uma situação econômica implica em perda para algumas pessoas, ela também possui características que permitem a compensação para balancear essa perda, de tal sorte que "a eficiência será alcançada se os ganhos de um agente puderem compensar a perdas de outro agente" (LEURQUIN e VIEIRA, 2011).

Sem a pretensão de esgotar tais conceitos nas linhas acima volvidas os pressupostos resumidamente apresentados até aqui se mostram suficientes para o objetivo deste trabalho, razão pela qual será dado doravante o enfoque necessário que justifique a relação da análise econômica do direito de modo a se alcançar a dignidade da pessoa humana, com uma tributação mais eficiente.

\section{Revista Brasileira de Direitos e Garantias Fundamentais| e-ISSN: 2526-0111| Encontro Virtual | v. 6 | n. 2 | p. 39 - 56| Jul/Dez. 2020.}




\section{PROTEÇÃO DOS DIREITOS FUNDAMENTAIS NA ERA TECNOLÓGICA}

Busca-se neste tópico estabelecer uma diferença conceitual entre direitos fundamentais e direitos humanos e posteriormente verter a análise da proteção dos direitos fundamentais na era tecnológica, para ao final conjugá-lo com a Análise Econômica do Direito.

A proteção dos direitos fundamentais na era tecnológica se inclina para o resguardo a partir da Constituição Federal e a preocupação com todos os reflexos do mundo virtual é irrefutável.

Aparentemente o descompasso entre vivência e regulação das relações sociais, e o virtuoso processo de inovação tecnológica é sentido de outro modo por RODOTÀ apud DONEDA (2000, p. 120):

\footnotetext{
Tem-se a sensação de que cresce a distância entre o mundo velocíssimo da inovação tecnológicas e o mundo lentíssimo da proteção sócio constitucional. Quase a todo momento percebe-se a rápida obsolescência das soluções reguladoras de um determinado fenômeno técnico, destinadas à solução de um problema apenas
}

Se Castells fala em uma sociedade em rede ou informacional, é necessário garantir o direito das pessoas de estarem e de se manifestarem na rede. Isto, pois "nossas sociedades estão cada vez mais estruturadas em uma oposição bipolar entre a rede e o ser", consequência do uso maciço das novas tecnologias. (LEVY, 1999, p. 204).

O autor afirma, no mesmo trecho, também que: "O Estado perde, assim, o controle sobre uma parte cada vez mais importante dos fluxos econômicos e informacionais transfronteiriços".

Segundo o pensamento do autor citado, a consideração de direitos humanos fundamentais pode não ser adequadamente instrumentalizada, portanto, em função deste limite territorial.

O autor citado desfere críticas a esse descompasso do universo tecnológicoinformacional e vida cotidiana, e a visão de que tecnologias determinam os rumos sociais, Castells (2003): 
É claro que a tecnologia não determina a sociedade. Nem a sociedade descreve o curso da transformação tecnológica, uma vez que muitos fatores, inclusive criatividade e iniciativa empreendedora, intervêm no processo de descoberta científica, inovação tecnológica e aplicações sociais de forma que o resultado depende de um complexo padrão interativo. Na verdade, o dilema do determinismo tecnológico é, provavelmente, um problema infundado, dado que a tecnologia é a sociedade, e a sociedade não pode ser entendida ou representada sem suas ferramentas tecnológicas.

Na discussão desse universo tecnológico se faz necessária a discussão dos direitos fundamentais e sua proteção pelo ordenamento jurídico uma vez que a sociedade segue clamando em face das novas necessidades e dos novos direitos assim descobertos.

Para tanto, necessária uma breve síntese de diferenciação formal, que entende que os direitos fundamentais estão vinculados a um ordenamento jurídico particular enquanto os direitos humanos possuem um caráter universal e "resultam de uma formulação internacional", sendo em função disto, mais amplos. (ANTUNES, 2005).

Segundo o autor os direitos humanos são fundamentais, embora nem todos o sejam, uma vez que os direitos fundamentais estão "aprisionados nas fronteiras de um Estado".

Nesse horizonte, os diretos fundamentais se posicionam numa dimensão mais restrita que os direitos humanos, na medida em que, segundo Canotilho estes "são direitos válidos para todos os povos e em todos os tempos (dimensão jusnaturalista-universalista)", razão pela qual, para o jurista português, "os direitos humanos" podem se tornar "direitos fundamentais" quando positivados. (CANOTILHO, 1993).

Os direitos fundamentais são, na sua dimensão natural, direitos absolutos, imutáveis e intemporais, inerente à qualidade de homem dos seus titulares, e constituem um núcleo restrito que se impõe a qualquer ordem jurídica. (ANDRADE, 2009, p. 21).

O aspecto mais importante da nova concepção de direitos fundamentais é a modificação do próprio sentido dos direitos e liberdades clássicas, a que passa a ser reconhecida uma nova dimensão e uma nova função. (ABRANTES, 2005, p. 218-219).

A partir dessas concepções se posiciona a doutrina pela recepção em sociedade de novos direitos assim denominados direitos de quinta geração que surgem com o uso da internet, e se verificam na atualidade em face necessidade de comunicação e se desdobra na 
também necessária emancipação enquadrando-os na seara dos direitos humanos. (PASOLD, 2005).

Igualmente, a consideração de tais direitos adequa-se com um dos pilares dos direitos humanos que é, justamente, a emancipação. (SANTOS, 1989).

O surgimento dos novos direitos é resultado de uma transformação de sociedade industrial para informacional.

Esta sociedade informacional tem como característica deste novo paradigma a "penetrabilidade dos efeitos das novas tecnologias", portanto, se a informação é necessária para as atividades humanas "todos os processos de nossa existência individual e coletiva são diretamente moldados (embora, com certeza, não determinados) pelo novo meio tecnológico." (CASTELLS, 1999).

A inclusão de novos direitos no rol dos direitos fundamental é possível, no ordenamento brasileiro, por meio da análise do parágrafo segundo do art. $5^{\circ}$. da Constituição Federal. Ele estabelece uma abertura à abrangência de novos direitos fundamentais “decorrentes do regime e dos princípios por ela [a Constituição] adotados". (CANOTILHO,1993).

Canotilho ensina que esta abertura dá vazão aos chamados "direitos materialmente fundamentais" em oposição aos "direitos fundamentais formalmente constitucionais", estes sim enunciados em normas constitucionais.

Assim, a garantia constitucional da efetividade dos direitos fundamentais, ainda que frente às novas tecnologias, deve ser o objetivo maior de qualquer Estado, que deve se utilizar de todos os métodos à sua disposição para alcançar tal intento.

\section{A AED E A EFETIVIDADE DOS DIREITOS FUNDAMENTAIS}

Ao tratar dos direitos fundamentais como forma de promover a concretização da dignidade da pessoa humana está-se invocando toda a gama de direitos das dimensões assim classificadas, não se limitando apenas as direitos econômicos, sociais e culturais, mormente porque traduzem o direito de todos à participação do bem-estar social, não se tratando, 
portanto, "de liberdade do e perante o Estado, e sim de liberdade por intermédio do Estado". (SARLET, 2012 - p. 33).

Tais direitos objetivam a garantia não apenas da liberdade e da autonomia frente ao Estado, mas também a "emancipação do ser humano por intermédio do Estado, sob a premissa de que para que o ser humano seja livre é preciso que tenha um nível de vida digno, em termos educacional, alimentar, cultural e de saúde". (OLIVEIRA e PAYÃO, s.d).

Nessa linha, tem-se que em todas as dimensões de direitos fundamentais, a noção de Estado de Direito e a existência da Constituição vinculam-se para juntos concretizarem o princípio da dignidade da pessoa humana. (SARLET, 2012 -p. 49).

Ocorre que, à medida que as projeções da pós-modernidade se concretizam, com ela se desenvolve um processo de ruptura entre o Poder e a Política, levando-se em consideração diversos fatores que, aliados aos impactos que a globalização promove, cria um ambiente econômico propício para o enfraquecimento das funções institucionais do Estado, o que repercute diretamente na efetivação das políticas públicas. (OLIVEIRA e PAYÃO, s.d).

Com isso "o Estado se debilita, na medida em que vai perdendo o domínio sobre as variáveis que influem na sua economia", de forma que se deteriora a sua capacidade de “formulação e implementação de políticas públicas, de regulamentação e fiscalização do seu mercado interno, e, com isso, o seu poder de garantir a eficácia dos direitos sociais" o que afeta a força constitucional pela observância e manutenção das garantias fundamentais. (OLIVEIRA e PAYÃO, s.d).

Nesse sentido, a complexidade da sociedade contemporânea "realça o disparate entre a escassez de recursos e as crescentes demandas fundadas nos direitos fundamentais e, quando instado a agir, o Estado, acaba posto frente às escolhas trágicas”. (OLIVEIRA e PAYÃO, s.d). Aqui neste ponto é que se propõe uma análise econômica do direito, com todos os seus pressupostos próprios, a fim de dar suporte às escolhas do Estado, para que sejam racionais, concretas, econômicas e eficientes, notadamente diante da inafastabilidade deste em promover a dignidade de seus governados:

A expressão "escolhas trágicas" tem como fundamento uma das premissas fundamentais da economia: os recursos são escassos e as demandas infinitas. E esta

\section{Revista Brasileira de Direitos e Garantias Fundamentais| e-ISSN: 2526-0111| Encontro Virtual | v. 6 | n. 2 | p. 39 - 56| Jul/Dez. 2020.}


condição é inescapável na oportunidade da elaboração de uma política social. (OLIVEIRA e PAYÃO, s.d, p. 13).

Aqui, não obstante as dificuldades vivenciadas pelo Estado quando instado a agir, a solução talvez esteja em priorizar "determinadas políticas que estejam diretamente ligadas às pré-condições de um processo de desenvolvimento, como é o caso da saúde e educação básica. Eis a luz do "mínimo existencial"” (OLIVEIRA e PAYÃO, s.d), assim:

A conjuntura socioeconômica pós-moderna e a repercussão na concretização dos direitos fundamentais é um convite à reflexão a respeito das potencialidades da análise econômica do direito como contribuição à plena efetividade constitucional. (OLIVEIRA e PAYÃO, s.d, p. 14).

Nesse sentido, de forma a trazer uma contribuição da análise econômica do direito à concretização dos direitos fundamentais, nota-se que o direito não se presta exclusivamente a tratar da eficiência, mas sim da justiça, entretanto, em diversas situações se faz necessário dialogar com ambas, interação que faz gerar "incentivos para que as pessoas se comportem de maneira mais produtiva, num grau de eficiência econômica tendente à realização de objetivos constitucionais, como o desenvolvimento nacional”. (OLIVEIRA e PAYÃO, s.d).

Segundo Oliveira e Payão (s.d. p. 16) é por meio dessa interdisciplinaridade que esse aumento de produtividade pode gerar uma "maior justiça social em virtude de regras de redistribuição de riquezas e redução de desigualdades”.

Portanto, admitindo-se a escassez de recursos da sociedade, notadamente para a concretização dos diversos direitos sociais, além dos interesses perseguidos pelo Estado, premente se mostra a necessidade da sociedade realizar escolhas entre as alternativas possíveis, o que atrai um dos pressupostos fundamentais da análise econômica do direito, qual seja, a racionalidade do comportamento humano frente a escassez. (CAMPOS e RIBEIRO, 2012).

Nesse ponto é importante ter em mente que a análise econômica do direito não deve ser levada a cabo pelo Estado apenas como forma de influenciar o comportamento das pessoas diante de uma norma jurídica, ele deve também se ver como um agente racional, que faz suas escolhas de forma a ter eficiência diante da escassez de recursos, mas igualmente 
promovendo justiça social, de modo a conferir a máxima efetivação de direitos, e aqui com destaque para os direitos fundamentais, com o mínimo de custos possíveis.

Ou seja, promover-se-á o máximo de bem-estar social com o máximo aproveitamento de recursos. Obviamente que não se pretende a extirpação de um direito de minorias, por exemplo, para dar lugar à eficiência, mas o que se sugestiona é a utilização dessa interação naquilo em que não conflitar com outras garantias fundamentais, de forma a dar a máxima efetividade e concretização desses postulados constitucionais. Aqui a “eficiência econômica irá possuir o sentido de maximização de determinados bens sociais eleitos como sendo de significativa importância." (SILVEIRA, 2009).

Ao se falar em eficiência da atuação estatal na concretização dos direitos fundamentais, "quer-se dizer a máxima efetivação de tais direitos, com a aplicação mais adequada dos recursos, sempre observando as limitações dos valores éticos e morais reconhecidos pela sociedade”. (CAMPOS e RIBEIRO, 2012).

Assim, compreendido o contexto de aplicabilidade da análise econômica do direito no ordenamento jurídico é seguro dizer que esta poderá ser útil para "avaliar os efeitos econômicos das leis e das orientações jurisprudenciais, de modo a orientar que sejam formuladas da maneira que produza melhores efeitos para fins de concretização dos direitos fundamentais" (CAMPOS e RIBEIRO, 2012), sempre com vistas ao máximo aproveitamento dos recursos que, como dito, são escassos.

\section{A AED E A TRIBUTAÇÃO EFICIENTE}

Relacionando a análise econômica do direito com os tributos, uma vez que mesmo “Adam Smith considerava que os tributos são 'preços' a serem pagos para o fornecimento de três categorias de bens públicos para seus súditos: defesa, justiça e bens públicos sujeitos a externalidades (SILVEIRA, 2009), tem-se que:

o Estado deve implementar suas políticas com o mínimo de efeitos para a sociedade ("minimum loss to society"). Minimizar seus efeitos é uma das exigências da eficiência econômica. Por outro lado, o Estado deve agir para obter a mais eqüitativa distribuição de bens na sociedade, especialmente, perante o fato de vivermos em

Revista Brasileira de Direitos e Garantias Fundamentais | e-ISSN: 2526-0111| Encontro

Virtual | v. 6 | n. 2 | p. 39 - 56| Jul/Dez. 2020. 
uma sociedade em que o mercado é imperfeito e existem motivações decorrentes de vontade de promoção de políticas públicas de bem estar social ("welfare-motivated policies"). (SILVEIRA, 2009, p. 6).

A tributação é considerada um "fenômeno sistêmico que envolve a Política, a Economia e o Direito", na medida em que do ponto de vista da Política deve ser considerada a relação entre poder e não poder de tributar, do ponto de vista da Economia a tributação é vista pelos agentes econômicos com um fator que pode alterar as situações de produção, acumulação e circulação de bens em uma sociedade, sendo que do ponto de vista do Direito este irá considerá-la como um conjunto de "expectativas institucionalizadas que dizem como os outros se comportem nas relações entre o poder de tributar e as limitações a este poder, determinando as sanções pelo descumprimento dessas normas condicionais;”. (SILVEIRA, 2009).

Silveira (2009, p. 14) ao tratar das contribuições e limites do direito tributário do ponto de vista da análise econômica do direito traz eu seu artigo, devidamente referenciado neste trabalho, importante contribuição para a compreensão de uma tributação eficiente que observe as garantias fundamentais:

Desse modo, outra característica decorre do sistema de deveres fundamentais, aquela
que exige que exista uma interpositio legislatoris que os concretize e os torne
aplicáveis pela Autoridade. O entendimento da importância institucional dos deveres
fundamentais como forma de financiamento dos direitos fundamentais é um dos
elementos mais destacados deste novo enfoque, bem como da compreensão de como
os custos de transação podem influenciar a eficiência econômica e a geração de
prosperidade para uma nação. A tributação deve ser enxergada, portanto, como uma
peça chave na realização geral de eficiência do sistema e como mecanismo
promoção de instituições que promovam o desenvolvimento e não que transfiram
recursos para uma classe política ou econômica privilegiada.

A Constituição Federal Brasileira reconheceu como um dos fundamentos da República Federativa do Brasil a dignidade da pessoa humana (art. $1^{\circ}$, inciso III). Como forma de efetivar tal fundamento trouxe também rol de direitos e garantias constitucionais, previstos em sua maioria no artigo $5^{\circ}$ da referida Carta.

Dentre tais garantias destacam-se, exemplificadamente, a liberdade no exercício de qualquer trabalho, ofício ou profissão (inciso XIII), a livre locomoção no território nacional em tempo de paz (inciso XV), a criação de associações e de cooperativas (inciso XVIII), a 
garantia do direito de propriedade (inciso XXII), a submissão da apreciação pelo Poder Judiciário de lesão ou ameaça a direito (inciso XXXV), a fruição plena dos direitos trabalhistas previstos no artigo $7^{\circ}$ dentre outros.

Destacando-se os exemplos citados acima nota-se que a sua fruição não está isenta do pagamento de algum tributo envolvido, seja ele sobre a renda, sobre o capital, sobre o consumo ou sobre a folha de pagamentos. (SILVEIRA, 2009). Neste ponto, necessária uma breve análise acerca dos pontos tratados anteriormente, quais sejam, a renda, o capital e o consumo.

Relativamente à tributação incidente sobre a renda esta "deve agir de modo a influenciar o mínimo possível a oferta de trabalho, sem estimular o mercado informal, reduzindo o mínimo a renda pessoal"; em relação ao capital a tributação deve procurar incentivar a poupança, de modo assegurar uma "tributação progressiva com alíquotas decrescentes, ou seja, menor quanto maior o tempo passar entre a aplicação e o resgate"; do ponto de vista do consumo os efeitos da tributação dependem da capacidade de realização de escolhas econômicas e mudanças de comportamento, de forma a se alcançar a neutralidade fiscal com a diminuição dos efeitos da tributação sobre setores rígidos, a fim de não criar ineficiências no sistema, "provocando um enfraquecimento do lado da oferta (produção) ou do consumidor, o que em longo prazo pode implicar em sérias distorções no sistema produtivo ou na renda geral da sociedade”. (SILVEIRA, 2009).

Portanto, resguardada a necessidade de uma análise mais aprofundada dos temas tratados neste trabalho relativamente à economia, aos princípios fundamentais e às questões sensíveis dos aspectos tributários, cada qual com a sua historicidade e carga teórica que os justificam, é possível vislumbrar a estreita relação entre a análise econômica do direito aplicada à tributação, como forma de garantir a máxima eficácia dos direitos fundamentais, seja na prestação de serviços públicos, políticas públicas e econômicas, seja na forma de tributar, de maneira que onere menos os atores sociais para que se estes se vejam livres e aptos a gozarem de uma vida digna que lhes promova o máximo de bem-estar social possível, ao menor custo, sem que isso também afete os cofres públicos. 


\section{CONSIDERAÇÕES FINAIS}

O estudo da análise econômica do direito a despeito de provocar divergência de opinião no meio acadêmico merece ser considerado em muitos, para não dizer todos, os ramos do Direito, uma vez que aceitar que os diversos ramos das ciências sociais dialoguem entre si pode ser benéfico quando dessa interação emprestam-se conceitos, pressupostos e princípios capazes de conferir maiores ganhos de eficiência numa determinada área de análise.

Nesse sentido, quando se trata de conferir aplicabilidade e efetividade aos direitos fundamentais, notadamente para a concretização da dignidade da pessoa humana, necessário ceder aos métodos de análise e de solução disponíveis, em nome da efetividade de tais direitos, ainda que sejam de outras áreas diferentes da do Direito mas que, de alguma forma, guardem uma certa similitude e conformação entre si, uma vez que, diante de uma sociedade cada vez mais tecnológica a interdisciplinaridade é uma tônica que ecoa por todos os lados, situação que, se bem trabalhada, pode somar forças e contribuir para todas as áreas relacionadas.

Dessa interação, de aliar a Economia ao Direito, de modo a não desconsiderar os preceitos de justiça, mas também almejando esta com a máxima eficiência e o melhor aproveitamento dos recursos, que são escassos, tem-se uma melhor maneira de gerir a máquina pública a favor dos administrados, tudo com vistas de efetivar a dignidade da pessoa humana, do ponto de vista dos deveres fundamentais do Estado, o que confere maior amplitude e permanência no momento de ver em funcionamento as garantias fundamentais.

Neste ponto, uma tributação eficiente poderá promover a aplicação de tais direitos de forma a conferir maior carga de concretização às garantias fundamentais tão caras num Estado Democrático de Direito.

\section{REFERÊNCIAS}

ABRANTES, José João. Contrato de trabalho e direitos fundamentais. Coimbra, 2005, p. 218-219.

ANDRADE, José Carlos Vieira. Os direitos fundamentais na Constituição Portuguesa de 1976. 4. ed. Almedina, 2009, p. 21. 
ANTUNES, Ruy Barbedo. Direitos fundamentais e direitos humanos: a questão relacional. Revista da Escola de Direito de Pelotas. v. 6 (1), Jan-Dez./2005, p. 334.

BRASIL. Constituição da República Federativa do Brasil de 1988. Brasília, DF: Presidência da República, 1988. Disponível em:

<http://www.planalto.gov.br/ccivil_03/constituicao/constituicao.htm>. Acesso em: 11 de setembro de 2020.

CANOTILHO, José Joaquim Gomes. Ibid., p. 528. No mesmo sentido ALEXY, Robert. Teoria de los derechos fundamentales. Trad. VALDÉS, Ernesto Garzón. Madrid: Centro de Estudios Constitucionales, 1993, p. 70-71.

CASTELLS, Manuel. A sociedade em rede. 6. ed. São Paulo: Paz e Terra, 1999, p. 108

DONEDA, Danilo Cesar Maganhoto. Considerações iniciais sobre bancos de dados informatizados e o direito à privacidade. In: TEPEDINO, Gustavo (org.) Problemas de direito civil-constitucional. Rio de Janeiro: Renovar, 2000, pp. 111-136.

HEINEN, Luana Renostro. A Análise Econômica do Direito e os pressupostos irrealistas da economia neoclássica.Disponível em:

<http://www.publicadireito.com.br/artigos/?cod=991c0955da231335>. Acesso em 15 de setembro de 2020.

LÉVY, Pierre. Cibercultura. São Paulo: Ed. 34, 1999, p. 204.

OLIVEIRA, Emerson Ademir Borges de; PAYÃO, Marília Jordana Viana. Direitos fundamentais na pós modernidade sob a perspectiva da análise econômica do direito fundamental. Revista da Faculdade Mineira de Direito. V.21 N.41.

PASOLD, Cesar Luiz. Novos Direitos: conceitos operacionais de cinco categorias que lhes são conexas. Revista Sequência, n. 50, jul. De 2005, p. 224.

RAMALHO, Ana Paula Ferreira de Almeida Vieira. A tributação como instrumento de redução da desigualdade econômica no estado social: críticas à atual progressividade do imposto de renda. 2020. 192 f. Dissertação (Mestrado em Direito) - Faculdade de Direito, Universidade Federal do Ceará, Fortaleza, 2020. Disponível em:

<http://repositorio.ufc.br/handle/riufc/51457>. Acesso em 18/09/2020.

RIBEIRO, Marcia Carla Pereira Ribeiro. Análise econômica do direito e a concretização dos direitos fundamentais. Revista de Direitos Fundamentais e Democracia. Curitiba, v. 11, n. 11, p. 304-329, jan./jun. 2012. Disponível em:

$<$ https://revistaeletronicardfd.unibrasil.com.br/index.php/rdfd/article/view/266>. Acesso em 20 de setembro de 2020.

Revista Brasileira de Direitos e Garantias Fundamentais| e-ISSN: 2526-0111| Encontro Virtual | v. 6 | n. 2 | p. 39 - 56| Jul/Dez. 2020. 
SALAMA, Bruno Meyerhof. O que é "direito e economia?" Uma introdução à epistemologia da disciplina para o estudante, o profissional e o pesquisador em direito. Artigos Direito GV. 2007. Disponível em:

<https://bibliotecadigital.fgv.br/dspace/bitstream/handle/10438/2773/WP3.pdf >. Acesso em: 01 de agosto de 2020.agenda

SANTOS FILHO, Sirio Vieira dos. A eficiência sob a perspectiva da análise econômica do direito. Justiça do direito v. 30, n. 2, p. 210-226, 2016. Disponível em < http://seer.upf.br/index.php/rjd/article/view/6040 >. Acesso em 19 de setembro de 2020.

SANTOS, Boaventura de Sousa. Os direitos humanos na pós-modernidade. Oficina do CES Centro de Estudos Sociais, Coimbra, n. 10, junho de 1989, p. 3.

SARLET, Ingo Wolfgang. Wolfgang A eficácia dos direitos fundamentais: uma teoria geral dos direitos fundamentais na perspectiva constitucional. Ed. 11, rev. atual. Porto Alegre: Livraria do Advogado Editora, 2012.

SILVEIRA, Paulo Antônio Caliendo Velloso. Direito Tributário e análise econômica do Direito: contribuições e limites. Revista da FESDT. Porto Alegre. já./jun. 2009. Disponível em: <https://www.fesdt.org.br/web2012/revistas/3/11.pdf.> Acesso em 17 de setembro de 2020 .

SIQUEIRA, Natércia Sampaio. Modelo de tributação adequado ao desenvolvimento sustentável. p. 55, Joaçaba: Editora Unoesc, 2019.

TRAMONTINA, Robison; SCHNEIDER, Yuri; Schawarz, Rodrigo Garcia. Direitos fundamentais sociais e políticas públicas como instrumento de efetivação desses direitos. Joaçaba: Editora Unoesc, 2015.

VIEIRA, Bruno Fernandes; LEURQUIM, Pablo Georges Cícero Fraga. A análise econômica do direito como método do direito econômico. XX Congresso Nacional do CONPEDI. Florianópolis: Fundação Boiteux, 2011. 